\title{
A GESTÃO DO CURRÍCULO NAS MALHAS DAS REDES POLÍTICAS EM ESCALA TRANSNACIONAL
}

\author{
Juares da Silva Thiesen ${ }^{(*)}$
}

A problemática que acolho para organizar o presente texto está inscrita no conjunto dos objetos de pesquisas com os quais venho me ocupando na Universidade. Refiro-me a uma pauta que se encontra em curso no contexto transnacional, bastante conhecida e que aqui denomino agenda propositiva global ${ }^{1}$. Movimento que embora apareça na cena política, na produção acadêmica e nos espaços da educação desdobrado em pontos ou conteúdos distintos, na origem e motivação, possui fundamentos e propósitos comuns. Trata-se de um conjunto de estratégias de ordem política e econômica, engendrado no âmbito das ações do chamado estado-mercado como redes políticas ${ }^{2} \mathrm{e}$ colocado na rota na educação na forma de grandes prescrições ou de políticas educacionais e curriculares desdobradas em definições e orientações distintas.

$\mathrm{Na}$ ordem dos discursos esta pauta é manifestada fixando-se o sentido de numa agenda propositiva em escala global ou transnacional ${ }^{3}$ que na educação, envolve pelo menos quatro grandes frentes, a saber: um movimento pela internacionalização curricular; a estratégia de centralização e/ou unificação curricular nas esferas nacional e regional; a universalização das avaliações em larga escala e o fortalecimento das chamadas parcerias público-privadas no território curricular. Em geral, na rota do discurso político e não raramente nos textos da política curricular oficial elas aparecem fixando sentidos em torno de conceitos como eficiência, inovação e qualidade.

Obviamente que, dado o limite deste trabalho e considerando a extensão e a complexidade da problemática, não pretendo abarcá-la na sua totalidade, até porque há uma vasta produção científica que a analisa e interpreta em diferentes perspectivas teóricas. Proponho, como recorte,

\footnotetext{
${ }^{(*)}$ Doutor em Educação. Professor do Centro de Educação da Universidade Federal de São Carlos (UFSC). Professor do Programa de Pós-graduação em Educação. E-mail: juares.thiesen@ufsc.br

${ }^{1}$ Ball (2014) denomina este movimento de "agenda político-econômica mundializante com interconexões globais que impactam a Educação". Dale (2004) a intitula "agenda globalmente estruturada para a educação".

${ }^{2}$ Para Ball (2014) as redes políticas constituem uma nova forma de governança, embora não de uma forma única e coerente, e colocam em jogo, no processo de políticas, novas fontes de autoridade [...] as fronteiras entre o Estado, a economia e a sociedade civil estão ficando turvas; há novas vozes nas conversas sobre as políticas e novos canais por meio dos quais os discursos sobre as políticas introduzem o pensamento sobre políticas.

${ }^{3}$ Maria de Fatima Cossio (2015) organizou um texto que e intitulou "Agenda transnacional e governança nacional: as possíveis implicações na formação e no trabalho docente".
} 
discuti-la dando ênfase a relação entre os sentidos acionados para hegemonização desta agenda e as reverberações deste movimento na gestão curricular em níveis locais, com especial atenção aos deslocamentos que ocorrem na gestão dos sistemas, de redes municipais de educação e em escolas.

Como pressuposto parto de duas (re)afirmações com as quais trabalho ao longo do texto. A primeira é que as prescrições desta anunciada agenda propositiva colocada na rota da educação pública predominantemente pelo território do currículo constitui parte de um projeto político e econômico único, articulado na esfera do estado-mercado e que tem sua marca discursiva na fixação do conceito de formação-serviço-eficiência e inovação-qualidade. A segunda, decorrente da anterior, é que a luta pela hegemonização deste regime de verdade ${ }^{4}$ vai discursivamente atingindo, como avalanche, toda a extensão da formação escolar e acadêmica desde os espaços da produção das políticas até os ambientes das instituições escolares, mobilizando tensionamentos, consensos, negociações, releituras, traduções, resistências.

É, pois, um movimento que por apresentar-se como agenda global e caracterizar-se como de interesse social promove determinados deslocamentos tanto em termos de linguagem quanto de práticas nos modos de gestão nos processos da formação escolar em geral e das dinâmicas de organização do currículo em particular.

Defendo que não obstante haver, nestas últimas décadas, certo esvaziamento de espaço nos discursos das políticas oficiais, ${ }^{5}$ a capacidade de mobilização na hegemonização de sentidos segue sendo considerável, especialmente quando vozes são entonadas em escala global por (e a partir dos) organismos e instituições transnacionais socialmente reconhecidas e chanceladas oficialmente nos espaços nacionais pelos estados. Parto, portanto, da premissa que embora o texto da política não coincida com a ação dos sujeitos materializada nos acontecimentos da formação, ele implica em vários aspectos, notadamente na dinâmica da gestão curricular que, de vários modos, responde demandas institucionais e políticas que lhe são colocadas.

Interessa-me, neste trabalho, portanto, identificar possíveis interfaces e/ou aspectos comuns presentes nas quatro frentes/pautas anteriormente destacadas de modo a afirmar que elas compõem uma unidade enquanto projeto global e, com este quadro, apontar e discutir deslocamentos e

\footnotetext{
${ }^{4}$ Para Foucault (1986), cada sociedade tem seu regime de verdade, sua política geral de verdade: isto é, os tipos de discurso que ela acolhe e faz funcionar como verdadeiros; os mecanismos e instâncias que permitem distinguir os enunciados verdadeiros dos falsos, a maneira como se sanciona uns e outros; as técnicas e os procedimentos que são valorizados para a obtenção da verdade; o estatuto daqueles que têm o encargo de dizer o que funciona como verdadeiro.

${ }^{5}$ Discussão sobre este aspecto pode ser encontrada no texto: "Discursos nas Políticas de currículo" de Alice Lopes (2006)
} 
reconfigurações que ocorrem atualmente em termos de discursos, princípios e procedimentos na gestão curricular no âmbito de escolas, sistemas e redes de ensino, mobilizados que são pelas influências de contextos externos, especialmente as derivadas desta macro-estratégia política e econômica que coloca a educação como um serviço (CHAUI, 2003) e a formação humana a serviço da eficiência-produção (ALMEIDA; ALMEIDA FILHO, 2013). Como primeira tarefa, destaco, ainda que brevemente, aspectos sobre esta agenda/pauta, para, em seguida, apontar como a tentativa de hegemonização de seus discursos provocam deslocamentos na gestão dos currículos em contextos locais.

\section{AGENDA/PAUTA DAS REDES POLÍTICAS EM ESCALA TRANSNACIONAL: IMPLICAÇÕES NA EDUCAÇÃO E NO CURRÍCULO EM CONTEXTO BRASILEIRO}

Trabalhos como o de Dale (2004, 2008), Ball (2014) e Cossio (2015), dentre outros, vêm apontando a existência de redes políticas em escala transnacional em cuja mobilização incluem, dentre outros aspectos, o monitoramento e controle de resultados educacionais por via de avaliações em larga escala, a centralização de decisões curriculares na formação escolar com base na perspectiva das culturas comuns, o estabelecimento de padrões internacionais para a formação básica e superior e o estímulo ao fortalecimento de parcerias entre estado e mercado com vistas ao desenvolvimento dos serviços educacionais. Esta agenda/pauta foi desencadeada concomitantemente e com força a partir da década de $1990,{ }^{6}$ especialmente no contexto dos países centrais, do norte, em meio ao movimento da chamada reestruturação econômica caracterizada, segundo Costa e Godoy (2008) pela,

flexibilidade dos processos de trabalho, dos produtos e padrões de consumo; surgimento de serviços financeiros e novos mercados; manutenção de taxas altamente intensificadas de inovação comercial, tecnológica e organizacional; rápidas mudanças dos padrões do desenvolvimento desigual, tanto entre setores como entre regiões geográficas; valorização do trabalho no setor de serviços; e, finalmente, a inserção de conjunto e práticas industriais em áreas até então, pouco industrializadas que utilizam estratégias arrojadas de atração de capital, mão de obra barata, isenção de imposto e baixo custo de instalação das empresas.

\footnotetext{
${ }^{6}$ Para Chizzotti e Ponce (2012) a ressurgência da pauta liberal está bem definida na Education Reform Act proposta pelo Estado britânico em 1988, sob o governo de Margareth Tatcher, mantida pelo partido New Labor de Blair. O objetivo prioritário dessa política curricular na Inglaterra foi elevar os standards, de performance a modelo dos estabelecimentos de ensino.
} 
Para Dale (2008) e Ball (2014), o resultado dessa agenda em sido uma mega reestruturação da governança na educação, ${ }^{7}$ com o Estado perdendo seus poderes supostamente exclusivos na área e sendo reduzido à coordenação das novas atividades, atores e esferas através dos quais a governação educacional deve ser alcançada. Nesta área o processo foi e continua sendo marcado pela forte presença dos organismos multilaterais ${ }^{8}$ com seus textos prescritivos e estratégias de controle e monitoramento como também destacam enfaticamente os trabalhos de Oliveira (2001); Dourado (2002); Gentili (1998); Kuenzer (1997); Gewirtz e Ball (2011), Cossio (2015), além de outros.

De fato, conceitos como gerencialismo ${ }^{9}$ e governança, nas últimas décadas, passaram a implicar fortemente na gestão pública em geral e na educação em particular. Pieranti, Rodrigues e Peci (2008) afirmam que simultaneamente, nas décadas de 1980 e 1990, vários movimentos, abrigados na chamada New Public Management (NPM), especialmente nos países anglo-saxônicos, propunham soluções para a administração pública. Os pontos centrais deste modelo eram a adaptação e a transferência dos conhecimentos gerenciais desenvolvidos no setor privado para o público, pressupondo a redução do tamanho da máquina administrativa, uma ênfase crescente na competição e o aumento de sua eficiência. Já, a governança, segundo Peters e Pierre (1998), representou uma forma de contrapartida à concepção tradicional da administração pública tendo seus principais focos de análise nos limites da ação do governo, bem como nas possibilidades de relação entre governo e setor privado.

Evidentemente que a proposição destes modelos, à medida que foram compondo textos públicos dos organismos multilaterais e acolhidos na formulação das políticas do Estado, tornaramse discurso hegemônico no universo dos países alinhados ao capitalismo de mercado, inclusive no Brasil. Concordo com Medeiros e Rodrigues (2014), quando afirmam que o gerencialismo, com suas diversas adequações aos contextos na escala local/global vem sendo intensificado na proposição de políticas no Brasil, e evidenciado em vários estados brasileiros, por meio de programas e projetos considerados exitosos, servindo de inspiração para novos gestores. É o que se pode observar em âmbito educacional, por exemplo, com a implantação de políticas de

\footnotetext{
${ }^{7}$ Sobre o conceito de governança sugere-se o texto "A sociologia da educação e o estado após a globalização" de Roger Dale (2010).

${ }^{8}$ Dentre os organismos estão: A Organização das Nações Unidas (ONU); a Organização das Nações Unidas para a Educação, a Ciência e a Cultura (Unesco); a Organização para a Cooperação e Desenvolvimento Econômico (OCDE); o Banco Mundial e o Banco Internacional para Reconstrução e Desenvolvimento (BIRD).

9 Sobre este conceito, sugere-se o texto: Modelos organizacionais e reformas da administração pública. Leonardo Secchi. Revista de Administração pública, Rio de Janeiro, 43(2):347-69, mar./abr. 2009
} 
remuneração por desempenho, objetivadas no pagamento de bônus ou de salários adicionais em função dos resultados obtidos ou a experiência dos Procentros ${ }^{10}$ no modelo das escolas charters em Pernambuco.

Este modelo de governança gerencialista que integra a gestão pública aos interesses privados, que classifica a educação como um serviço, que se orienta pelo principio da eficiência com base em resultados, que estimula a competição e os ranqueamentos, que avalia por padrões externos, que descentraliza responsabilidades e controla recursos, constitui, portanto, significante que sustenta e mantém a hegemonia da pauta educacional colocada pela agenda política global na rota da educação, tanto na esfera transnacional quanto brasileira.

No que se refere às iniciativas mais diretamente relacionadas ao campo do currículo, são exemplos desta reestruturação, o processo de Bolonha assinado em 1999 (LEITE e GENRO, 2012); a criação do PISA (Programme for International Student Assessment) em 2000; as reformas curriculares em vários países centrais (Austrália, Inglaterra, Espanha, e outros); as políticas de accountability nos EUA, ${ }^{11}$ a criação e expansão de organizações não governamentais e institutos privados dedicados a oferta de soluções educacionais e curriculares para os sistemas públicos.

$\mathrm{Na}$ América Latina este movimento logo foi seguido pela implantação de Sistemas Nacionais de Avaliação em larga escala, a exemplo do México, Brasil, Chile, Colômbia, Honduras e em vários outros (BECKER, 2010); pelas iniciativas das agências de avaliação e fomento à educação as quais passaram a estimular ações para a internacionalização da Pós-Graduação e das Universidades (LEITE; GENRO, 2012); pelas reformas curriculares efetivadas na imensa maioria os países latinoamericanos visando garantir maior unidade nacional na formação escolar (DUSSEL, 2006; CASASSUS, 2001) e pela ampliação no número de organizações não governamentais e privadas destinadas a oferecer serviços educacionais aos sistemas e escolas publicas (PERONI, 2013).

No contexto Brasileiro, já em 1991, com o Governo Color de Melo, inicia-se a reforma do Estado com o chamado Projeto de Reconstrução Nacional no qual a educação foi considerada elemento necessário à reconstrução competitiva e deveria estar adequada às demandas da população e as necessidade econômicas do país (YANAGUITA, 2011). Seguiu com Itamar Franco no Plano Decenal para Todos (1993-2003) que, segundo Saviani (1999), foi formulado em conformidade

\footnotetext{
${ }^{10}$ Os Procentros foram criados pelo Dec. 26.307, de 15 de janeiro de 2004. Análise sobre este projeto pode ser encontrada na pesquisa de Rafaela Campos Sardinha que tem como título: O projeto PROCENTRO e as escolas charter: investigação de um modelo educacional defendido pela Fundação Itaú Social. Disp.: <http://www.educacao. ufrj.br/drafaelasardinha.pdf>.

${ }^{11}$ Recomendo a leitura do texto "School Accountability no Brasil: experiências e dificuldades", de Eduardo de Carvalho Andrade publicado na Revista de Economia Política em 2008.
} 
com o objetivo pragmático de atender a condições internacionais de obtenção de financiamento para a educação, em especial aquele de algum modo ligado ao Banco Mundial.

Depois, com Fernando Henrique Cardoso, os alinhamentos a esta agenda propositiva se acentuam seja pelo estabelecimento de novas formas de parcerias entre o estado e os setores produtivos da sociedade civil ou pela promulgação de um conjunto de leis e diretrizes, a exemplo da LDB (Lei 9394/96), dos Parâmetros Curriculares Nacionais em 1995, da criação do Exame Nacional de Curso - o "provão” também em 1995 e do Exame Nacional de Ensino Médio (ENEM) - criado em 1997, todos em acordo com preceitos e recomendações internacionais.

O ciclo é concluído nos governos Lula e Dilma (2003-2016) que não obstante haverem estimulado a formulação e implantação de políticas sociais substantivas, mantiveram pauta semelhante aos governos anteriores, especialmente no que se refere ao fortalecimento e criação de novas estratégias de avaliação externa, a exemplo do Sistema Nacional de Avaliação da Educação Superior - SINAES. Nesta mesma linha, incentivaram os ranqueamentos pela criação de indicadores de mensuração de desempenho a exemplo do IDEB criado em 2007 e do fortalecimento dos chamados critérios de produtividade na Pós-Graduação. Além disso, deram respostas efetivas às demandas da internacionalização especialmente pela criação do Programa Ciência sem Fronteiras e pelo próprio REUNI que estabeleceu como diretriz a ampliação da mobilidade estudantil, com a implantação de regimes curriculares e sistemas de títulos que possibilitem a construção de itinerários formativos, mediante o aproveitamento de créditos e a circulação de estudantes entre instituições, cursos e programas de educação superior (BRASIL, 2007).

Atualmente, a iniciativa mais evidente, no Brasil, visando responder demandas colocadas na agenda global, é o debate sobre a proposição de uma Base Nacional Comum Curricular (BNCC). Embora seja uma iniciativa ancorada no conjunto da normalização instituída pela Lei de Diretrizes e Bases (LDB) e contemplada no atual Plano Nacional de Educação, alinha-se às perspectivas de ajustamento dos sistemas de ensino às necessidades de institucionalização de formas de regulação e controle especialmente por meio de avaliação padronizada de resultados (FERNANDES, 2015). Revela-se, pois, no plano das convergências a um movimento de centralização e de controle curricular em curso nos contexto transnacional a que estamos nos referindo.

Observa-se, portanto, que esta agenda/pauta que integra vários projetos educacionais contém recomendações relativamente comuns em termos de concepção curricular, finalidades formativas e estratégias de ação. Em termos mais gerais, nota-se que há um evidente esforço articulado neste âmbito para hegemonizar a expectativa neoliberal que integra eficiência-inovação-qualidade, 
fixando-se a ideia que o caminho para o alcance deste patamar passa necessariamente pelo território curricular na formação básica e profissional. Além desta expectativa, como potência, várias outras, bem conhecidas, porque circulam amplamente desde os anos 1990, aparecem em significativo volume de textos que apresentam e discutem a agenda, dentre as quais a ideia de educação como estratégia para o desenvolvimento econômico, a importância das parcerias do setor público com a iniciativa privada, a relevância das novas tecnologias, a necessidade de novas formas de gerenciamento, a importância da implantação de mecanismos de acompanhamento, controle e avaliação dos sistemas e instituições educacionais, o fortalecimento da ideia de construção de culturas transnacionais, as vantagens do intercâmbio de saberes na escala local-global, dentre tantos outros. São enunciados que reverberam nas dinâmicas da gestão do currículo, especialmente na formulação das políticas locais, nas práticas e no monitoramento de resultados.

\section{PROPOSIÇÕES DA AGENDA/PAUTA POLÍTICA DAS REDES TRANSNACIONAIS: IMPLICAÇÕES NA GESTÃO CURRICULAR.}

No conjunto das expectativas e demandas geradas no âmbito desta pauta/agenda, encontramse, dentre outras, a da mobilidade estudantil e docente, a da formação inter e multicultural, a do currículo por competências e a da flexibilização, todas inter-relacionadas e com implicações na gestão curricular. Teichler (2004) aponta que a mobilidade é uma das principais formas de internacionalização curricular, razão pela qual constitui parte do planejamento estratégico de estados e instituições educativas. Tanto nas pautas da internacionalização quanto da centralização curricular a mobilidade aparece associada à proposta de acreditação, ${ }^{12}$ certificação e reconhecimento de títulos, ações que respondem ao conceito de migração estudantil e, por isso, mobilizam readequações locais em termos de oferta formativa.

O multilinguismo ${ }^{13}$ é outro conceito mobilizado nesta pauta, especialmente quando associado aos temas da internacionalização e da avaliação em larga escala com currículos de

\footnotetext{
${ }^{12}$ Para Polidori e Carvalho (2014), o processo de acreditação foi um dos produtos da criação do espaço europeu de Ensino Superior. A criação desse ideal surgiu a partir da Declaração de Bolonha determinando que deveria haver uma padronização do Ensino Superior ao que se refere a currículos e a forma de garantia da qualidade e também, promovendo deslocamentos de docentes e discentes dentro da União Europeia

${ }^{13}$ Sobre a importância do multilinguismo assim se expressa Oliveira (2010, p. 21) [...] chama a nossa atenção a velocidade dos processos e a 'nova centralidade' que ganha, no mundo todo, a questão das línguas. Há uma nova pressa, os diversos países agem com rapidez. Países que nunca trataram da questão das línguas apressam-se em elaborar programas. Países que tradicionalmente são 'clientes' de políticas linguísticas vindas de fora apressam-se em formular seus próprios delineamentos. Oficializam- -se novas línguas, reformam-se os sistemas de ensino de línguas estrangeiras, novas línguas lutam para entrar nos currículos, novos e grandes bancos de dados de línguas são financiados e
} 
privilegiam formação multilíngue ou vêm abrindo espaços nos seus projetos curriculares para a inclusão de componentes que promovam esta competência. Em geral, o discurso de indução ao multilinguismo está associado ao conceito de formação cosmopolita propagada como uma forma contemporânea de construção da cidadania mundial.

Expectativas de formação intercultural e multicultural aparecem dentre os ideários que compõem os discursos na agenda global e estão visivelmente manifestadas nos textos dos projetos que a compõem. É possível que esta recomendação seja uma das mais sedutoras e potentes em termos de hegemonização de sentidos e construção de consensos, sobretudo por estar associada a outros requerimentos contemporâneos da formação humana como diversidade, cooperação, interação, integração, mobilidade, cosmopolitismo. Nesse sentido, valoriza-se a necessidade universal de construção das chamadas competências inter ou multiculturais as quais incluem um conjunto de conhecimentos, habilidades, atitudes e valores, especialmente relacionados com as demandas do mundo globalizado que busca integrar massificação com diversidade cultural (RAMOS, 2007).

No Brasil, esta recomendação encontra ressonância em praticamente todos os textos oficiais da política curricular e vai rapidamente sendo incorporada nas proposições curriculares das organizações privadas que atuam com educação. Em geral, os currículos escolares são movidos na perspectiva de estimular a permanência do ensino/aprendizagem das culturas hegemônicas abrindo alguns espaços para as culturas locais, seja pelas fendas da chamada parte diversificada ou pelas pressões dos movimentos sociais de grupos que reivindicam a presença deste conhecimento/saber nos currículos.

Dentre as expectativas largamente demandadas na pauta destas redes políticas em escala transnacional está a do currículo por competências. Segundo Dale (2008), num contexto de economia global de conhecimento (EGC) e sob nova governação educacional, as demandas que antes prescreviam currículos baseados em conhecimento-conteúdos vão sendo rapidamente substituídas por conhecimento-competências. Nestes lugares da relação local-global as competências terão prioridade sobre o conhecimento de conteúdos, e o universalismo dá lugar a ofertas customizadas até alcançar a aprendizagens personalizadas.

Para Deluiz (2001) o debate a respeito do conceito de competências passa pelo seu entendimento no campo da educação, surgindo no bojo das discussões sobre o sistema educacional coloca no centro de disputas de hegemonia. 
frente às exigências de competitividade, produtividade e inovação do sistema produtivo. Como parte dos programas de reforma do Estado nos países latino-americanos, o sistema educacional vai sofrer alterações a partir da década de 1990, recebendo orientação e suporte financeiro de organismos internacionais, visando a articulação e subordinação da produção educacional às necessidades do mercado de trabalho e a necessidade da definição de mecanismos de controle e avaliação da qualidade do sistema de ensino. Maués, Wondje e Gauthier (2004) consideram que o modelo de competências aparece na educação brasileira como uma senha que vai permitir a entrada no mundo contemporâneo e o alinhamento com a tendência internacional no que se refere à educação.

No Brasil, a demanda por competências mostra-se evidente tanto nos textos das políticas curriculares quanto nos mecanismos de avaliação-controle dos resultados da formação escolar. Este requerimento está presente nas iniciativas estatais e nas ações resultantes de parcerias com a sociedade civil, a exemplo do que representaram os textos das Diretrizes Curriculares Nacionais promulgadas a partir de 2010 para a Educação Básica e Superior, a instituição de indicadores de avaliação externa também para os dois níveis de ensino, o fortalecimento do chamado currículo por competências e mais recentemente as prescrições do texto preliminar da Base Nacional Comum Curricular (BNCC), em discussão no país.

Ao hegemonizar o sentido de competências como um modelo de referência para a “formação escolar e profissional administrada" (SILVA, 2007) os agentes desta pauta buscam preencher e fixar seus significantes apontando e indicando quais competências são universalmente válidas e, portanto, devem compor o currículo tanto no âmbito da ação escolar quanto das prescrições. Constitui, pois, um movimento que avança, na correlação de forças com outros grupos sociais de menor expressão política, protagonizando escolhas curriculares, hierarquizando-as e marcando-as como referência para outros processos, inclusive a própria avaliação externa.

Neste âmbito, o conjunto das competências fixadas como estratégicas para o alcance dos padrões mínimos exigidos em escala nacional-global inclui as chamadas competências informacionais e lingüísticas, competências laborais ou profissionais e competências cognitivas, todas desdobradas num elenco de habilidades, atitudes e valores que são esperados enquanto resultados da formação. ${ }^{14}$

\footnotetext{
${ }^{14}$ Cardoso e Hora (2013) apontam alguns documentos oficiais que orientaram, ainda na década de 1990, o currículo por competências. Dente eles: A Conferência Mundial da Educação Para Todos - Tailândia (UNESCO, 1990); O Relatório para a Unesco da Comissão Internacional da Educação para o Século XXI (DELORS, 1998); e os Parâmetros Curriculares Nacionais (BRASIL, 1998).
} 
No Brasil algumas políticas curriculares foram e ainda são orientadas por matriz de competências a exemplo da Certificação por Competências Profissionais (MORAES; NETO, 2005); das Matrizes de Referência do Ensino Fundamental para Avaliação da Educação Básica (SAEB) (BRASIL, 2011) e do Currículo Referência para o sistema e-Tec Brasil (2010).

Nessa direção, as (re)configurações dos textos das políticas educacionais e curriculares produzidas nos espaços nacionais e locais vão acolhendo e, portanto, reterritorializando conceitos, ideários e prescrições hegemonizados em contextos transnacionais, fixando sentidos correspondentes ou com baixo nível de resistência. É, pois, um movimento que mobiliza os territórios da gestão curricular produzindo certos deslocamentos tanto no âmbito dos discursos quanto das ações.

Neste mesmo âmbito pode-se incluir outra demanda por fixação de sentidos como é o da flexibilização curricular que, na perspectiva da agenda global, opera com múltiplos significados, notadamente o de descentralização e o de adequação/adaptação. O primeiro, em geral, associado à ideia de ampliação de autonomia, antagonicamente move-se na direção da responsabilização (accountability) de sistemas e escolas em termos de alcance de metas e resultados. Ou como afirma Pacheco (2005), a forte flexibilidade que a globalização admite, estando neste aspecto muito próxima da pós-modernidade, não é mais do que um processo de criação de espaços de responsabilização dos sujeitos, cujas identidades devem estar circunstanciadas a compromissos, a metas a cumprir e a resultados a atingir. O segundo, (adaptação/adequação) ainda que procure fixar um sentido de ampliação da liberdade de escolhas e de organização curricular, contraditoriamente, permite ao Estado e ao mercado educacional garantir maior agilidade aos processos formativos, responder mais prontamente às demandas da mobilidade estudantil e, tornar a formação escolar mais alinhada aos princípios do grande projeto político em pauta.

Identificadas algumas interfaces entre os macro-projetos no contexto do que compõe esta agenda política global e apontadas repercussões nos espaços curriculares da formação escolar, passo a situar e discutir deslocamentos que ocorrem nos processos de gestão curricular no âmbito de escolas e sistemas de ensino no Brasil, com especial atenção às reconfigurações mais visíveis em termos de enunciados, fixação de princípios e procedimentos, movidos que são pelas correlações de força e/ou alinhamento aos movimentos da agenda transnacional.

Em termos de princípios, os deslocamentos em curso na gestão curricular, no Brasil, como vimos, são mobilizados pela força discursiva da racionalidade neoliberal que afirma a eficiênciainovação-qualidade como potência para os processos escolares da formação e vai compondo, neste 
quadro dinâmico, propostas que se alinhem ao macroprojeto da rede política global. Por acolhimento, sistemas e redes de ensino e escolas passam a operar na lógica destes princípios mobilizando redesenhos, readequações, ajustes, adaptações para os processos de ensino, aprendizagem, seleção dos repertórios de conhecimento, organização das matrizes curriculares, processos internos de avaliação, projetos pedagógicos, parcerias, formação continuada, etc.

Todavia, na correlação de forças, operam formas de resistência a esta racionalidade, mobilizadas por outras formas de significação. Em geral, são movimentos mais locais assumidos por coletivos de professores que mantém, no horizonte discursivo, metanarrativas de formação humana mais ampla que tentam escapar das amarras e armadilhas do mercado. No território do currículo, estes coletivos produzem a crítica aos mecanismos de gestão que passam a operar nesta perspectiva, a exemplo do quem tem sido a contestação ao projeto da Base Nacional Comum Curricular - BNCC, ao projeto Escola sem Partido, as parcerias com a iniciativa privada, aos mecanismos de avaliação externa, a Medida Provisória 746 da reforma do Ensino Médio e tantos outros.

Interessante observar que nas fronteiras que marcam estes espaços de luta por significação, alguns princípios passam a ser assumidos com sentidos distintos por ambos os movimentos, como é o caso da ideia da gestão democrática, de cidadania participativa e de descentralização. Para Mendes (2003), a concepção de democracia se desdobra em formas ideológicas bastante articuladas com os pressupostos gerenciais do Estado neoliberal, configurando-se uma maneira que permita mais funcionalidade à gestão dos processos de trabalho. Seu significado como prática onde os conflitos emergem é substituído pelo espírito de construção coletiva, onde o consenso se torna o imperativo. No entendimento do autor, os pressupostos democráticos são dessecados e a democracia negada na sua essência, entretanto, termos que a sugere são exaustivamente utilizados e incorporados às modernas modalidades de administração.

No que se refere a ideia de participação cidadã e descentralização, a luta por fixação de sentidos segue percurso similar. Na leitura que faz sobre esta fronteira discursiva, Mendes (2003, p. 5) ilustra com um exemplo interessante.

$\mathrm{Na}$ instituição escolar os atores sociais são mobilizados para o desenvolvimento de gestões democráticas orientadas pelas políticas públicas, respondendo, assim, ao chamamento à participação (outra novidade conceitual). O adjetivo da gestão aparece sem o conteúdo essencial, designando tão somente uma forma moderna de envolver todos na realização de atribuições funcionais à descentralização (conceito que ao lado de autonomia ameniza a racionalidade de um Estado Mínimo) das responsabilidades gestoras, diluídas em várias instituições componentes do Estado Mínimo. Esta descentralização das ações anteriormente 
sob responsabilidade do Estado incorpora o charme da repartição do poder reclamado há muito por movimentos sociais democráticos.

Além do exemplo de Mendes, acrescento o de Peroni (2012) que ilustra bem como os conceitos de democracia, participação e descentralização são operados nos espaços da gestão educacional, escolar e do currículo. A pesquisadora aponta o caso do Programa PDE-Escola ${ }^{15}$ que segundo ela, está orientado por uma gestão de natureza gerencial, mas que oferece a formação 'Escola de Gestores', um curso de especialização para diretores de escolas públicas que tem toda a sua proposta curricular e seu formato no sentido de fortalecer a gestão democrática da educação. A pesquisadora destaca ainda a avalanche de contratos firmados por escolas públicas com organizações privadas envolvendo soluções curriculares, todos vendendo estes mesmos conceitos.

Na gestão, portanto, deslocam-se princípios e, por extensão, redefinem-se procedimentos. É o movimento presente nos cenários dos sistemas de ensino e de escolas brasileiras atualmente. Com a hegemonização de discursos que se fixam em torno de ideários de uma educação performativa, eficiente, utilitária, inovadora, com padrões de qualidade, vários procedimentos de gestão se alteram.

É perceptível, por exemplo, a invisibilização do debate sobre eleição direta para diretores, procedimento que vai sendo substituído pela proposição de "planos de gestão" (SANTA CATARINA, 2013; e DRABACH, 2013). ${ }^{16}$ Igualmente visível é a retração dos espaços políticos e pedagógicos dos projetos das escolas em razão de expectativas geradas pela possibilidade de participação destas unidades nos programas centralizados do Governo Federal, a exemplo do Programa Dinheiro Direto à Escola (PPDE), do Plano de Desenvolvimento da Educação (PDE)Escola, do Programa Mais Educação, do Programa Ensino Médio Inovador (ProEMI), além de vários outros que orientam e, em alguns casos, redefinem os projetos pedagógicos e a estrutura curricular das escolas públicas.

Somados aos exemplos anteriores, movem-se vários outros processos internos com perspectiva semelhante como é a instituição, pelos próprios sistemas municipais, de programas de avaliação de rendimento escolar; a instituição dos chamados sistemas de vouchers que estimula a meritocracia e aproxima os comportamentos entre escola pública e privada (CUNHA, 2008); a ampliação do número de eventos de simulação de provas como preparação de estudantes para testes em avaliação externa, o crescente número de projetos que propõem ampliação de jornada escolar

\footnotetext{
${ }^{15}$ Plano de Desenvolvimento da Educação

${ }^{16}$ O processo que institui o Plano de Gestão para provimento do cargo de Diretor de Escola em SC segue o Decreto 1.794, de 15 de outubro de 2013, e as alterações introduzidas pelo Decreto $S C \mathrm{n}^{\circ} 243$, de $1^{\circ}$ de julho de 2015.
} 
com atividades de contraturno focados tão somente no reforço escolar e na consequente melhoria dos indicadores de sucesso escolar; a implantação de projetos de correções de fluxo com vistas a equalizar a distorção idade-série; a visível ampliação da carga horária de disciplinas de língua estrangeira na Educação Básica; a compra e venda de kits com material didático e apostilas para uso dos professores - em geral, alinhados com estas novas demandas.

\section{ALGUMAS CONSIDERAÇÕES FINAIS}

A correlação de forças que se trava entre diferentes grupos sociais para fixar marcos e estabelecer regimes de verdade nos territórios curriculares vem tornando-se mais explicita e intensa. Ponce e Chizzotti (2012) afirmam que a competição internacional mobilizou os sistemas de ensino e trouxe o currículo escolar para o centro de uma vigorosa disputa econômica, política e cultural. Um campo de estudos e pesquisas que vem despontando como território nuclear na acirrada luta por hegemonias sejam elas epistêmicas ou políticas.

Na medida em que determinadas finalidades da formação escolar vão sendo discursivamente protagonizadas e fixadas como regimes de verdade e, portanto, hegemonizadas como de interesse social universal, vão ampliando-se as repercussões nos sistemas educacionais e nas escolas, em movimentos que incluem resistências, negociação, releituras, transgressões, traduções, etc. Os espaços da gestão curricular são, assim, fortemente implicados dado que neles se definem as estratégias e os procedimentos necessários para atingir determinados objetivos e metas.

Quando se analisa, com algum detalhe, o modo como se operam as estratégias discursivas no engendramento desta agenda/pauta das redes políticas em escala transnacional, fica evidente que seus atores (pessoas e organizações) lançam mão de toda a sorte de instrumentos técnicos e políticos mobilizando tanto os núcleos centrais das macro-estruturas da gestão educacional quanto os micro-espaços da gestão escolar visando fixar os sentidos que lhe são caros e consequentemente hegemonizá-los. Fazem isso acessando aos espaços da educação pública e assumindo, por vezes, com o Estado o protagonismo dos textos da política educacional e curricular.

$\mathrm{Na}$ microesfera da gestão curricular as ações se movem cambiantes por entre as fronteiras difusas das atuais tendências e expectativas em termos de ideário formativo, num horizonte cada vez mais marcado pelo slogan do mercado. Gestores dos sistemas escolares e das próprias escolas, tomados que são por esta avalanche discursiva e pela pressa exigida no alcance de resultados, vão conduzindo os processos como podem, resistindo ou negociando sentidos. Enfim, tentando responder a estas e várias outras demandas que lhe são cotidianamente colocadas. 


\section{REFERÊNCIAS}

ALMEIDA, Aléssio Tony Cavalcanti; ALMEIDA FILHO, Álvaro Cavalcanti. Eficiência técnica da gestão em educação básica da rede federal de ensino no Brasil. ANPAE, 2013.

BALL, Stephen J. Educação Global S. A.: novas redes de políticas e o imaginário neoliberal. Trad.: Janete Bridon. Ponta Grossa, Brasil: UEPG, 2014.

BECKER, Fernanda da Rosa. Avaliação educacional em larga escala: a experiência brasileira. Revista Iberoamericana de Educação, n. 53(1), p. .1-11, jun. 2010.

BRASIL. Currículo referência para o sistema e-tec Brasil: uma construção coletiva. Brasília: MEC: 2010. Disp.: <http://www.etec.ufsc.br/file.php/1/cr/pretextos/apres_Galo.html>. Acesso: 10 set. 2016.

BRASIL. Ministério da Educação. PDE: Plano de Desenvolvimento da Educação: Prova Brasil: Ensino Fundamental: matrizes de referência, tópicos e descritores. Brasília: MEC, SEB; Inep, 2008.

BRASIL. Ministério da Educação. REUNI: Reestruturação e expansão das Universidades Federais - diretrizes gerais. 2007. Disp.: <http://portal.mec.gov.br/ sesu/arquivos/pdf/diretrizesreuni.pdf>. Acesso em: 20 jul. 2016.

CARDOSO, M.C.; HORA, D.M. Competências e habilidades: alguns desafios para a formação de professores. HISTEDBR. Anais da XI Jornada... A Pedagogia Histórico-Crítica, a Educação Brasileira e os desafios de sua institucionalização. Cascavel-PR, Disp.: <http://www.histedbr.fe.unicamp.br/acer_histedbr/jornada/jornada11/artigos/ 7/artigo_simposio_7_713_micheli_ccardoso@yahoo.com.br.pdf. Acesso: 20 out. 2016.

CHAUI, Marilena. A universidade pública sob nova perspectiva. Revista Brasileira de Educação, n. 24, Set. /Out. /Nov. /Dez. 2003.

CHIZZOTTI, Antonio; PONCE, Branca Jurema. O currículo e os sistemas de ensino no Brasil. Currículo sem Fronteiras, v. 12, n. 3, p. 25-36, set./dez. 2012.

COSSIO, Maria F. Agenda transnacional e governança nacional: as possíveis implicações na formação e no trabalho docente. Revista e-Curriculum, São Paulo, v. 13, n. 04, p. 616-640, out./dez. 2015.

COSTA, Pedro H.F.; GODOY, Paulo R.T. O capitalismo contemporâneo e as mudanças no mundo do consumo. GEOCRIT. Actas del X Colóquio Internacional de Geocrítica. Universidad de Barcelona, mayo, 2008. Disp.: <http://www.ub.es/geocrit/-xcol/330.htm>. Acesso em: 05 set. 2016.

CUNHA, Rina N.D. Aplicação de vouchers para incentivo educação no Brasil. Dissertação (Mestrado em Finanças Economia Empresarial) - Fundação Getúlio Vargas, Rio de Janeiro, 2008. Disp.: <http://bibliotecadigital.fgv. br/dspace/bitstream/handle/10438/7906/000406515.pdf?sequence=1>. Acesso em: 05 set. 2016.

DALE, Roger. A globalização e o desenho do terreno curricular. Revista Espaço do Currículo, v. 1, n.1, p. 12-33, mar.-set. 2008.

. A sociologia da educação e o estado após a globalização. Educação e Sociedade, Campinas, v. 31, n. 113, p. 1099-1120, out.-dez. 2010 .

Globalização e educação: demonstrando a existência de uma "cultura educacional mundial comum" ou localizando uma "agenda globalmente estruturada para a educação". Educação e Sociedade, Campinas, vol. 25, n. 87, p. 423-460, maio-ago. 2004.

DELORS, J. Educação: um tesouro a descobrir. São Paulo: Cortez, Brasília: MEC, UNESCO, 1998.

DELUIZ, Neise. O modelo das competências profissionais no mundo do trabalho e na educação: implicações para o currículo. Boletim Técnico do SENAC, v. 27, n. 3, p. 13-25, set.-out. 2001.

DOURADO, Luiz F. Reforma do estado e as políticas para a Educação Superior no Brasil nos anos 90 . Educação e Sociedade, Campinas, vol. 23, n. 80, p. 234-252, set. 2002.

DRABACH, N. As formas de provimento à função de diretor escolar no Brasil a partir da Reforma do Estado de 1995. In: ANPAE. Anais do XXI Simpósio Brasileiro de Política e Administração da Educação. Recife/PE. Timbaúba/PE, 2013.

DUSSEL, Inés. Estudio sobre gestión y desarrollo curricular en países de América Latina. Santiago de Chile: Orealc/Unesco, may, 2006.

FERNANDES, Claudia O. Avaliação, currículo e suas implicações: Projetos de sociedade em disputa. Brasília: Revista Retratos da Escola, v. 9, n. 17, p. 397-408, jul.-dez. 2015. 
FOUCAUlT, M. Microfísica do Poder. Org. Roberto Machado. Rio de Janeiro: Graal, 1986.

GENTILI, P. A falsificação do consenso: simulacro e imposição na reforma educacional do neoliberalismo. Petrópolis: Vozes, 1998.

GEWIRTZ Sharon; BALL, Stephen F. Do modelo de gestão do bem estar social ao novo gerencialismo. In: Politicas educacionais questões e dilemas. São Paulo: Cortez, 2011.

KUENZER, A. Z. Ensino médio e profissional: as políticas do estudo neoliberal. São Paulo: Cortez, 1997.

LEITE, Denise; GENRO, Maria E. Herz. Avaliação e internacionalização da Educação Superior: Quo vadis América Latina? Campinas/Sorocaba/SP: Avaliação, v. 17, n. 3, p. 763-785, nov. 2012.

MAUÉS, O. C.; WONDJE, C.; GAUTHIER, C. Duas perspectivas diferentes em relação à abordagem por competências no ensino: os casos do Brasil e do Quebec. ANPED. GT Formação de Professores, n. 08. 2004. Disp.: <www.anped.org.br/25/olgaisesmauest08.rtf>. Acesso em: 07 set. 2016.

MEDEIROS, Sonayra S.; RODRIGUES, Melânia M. O gerencialismo, reforma do Estado e da educação no Brasil. Revista Educação em Questão, Natal, RN, v. 48, n. 34, p. 216-240, jan.-abr. 2014.

MENDES, J. E. Ideologia Neoliberal na política de gestão escolar. In: XVI Encontro de Pesquisa Educacional do Norte e Nordeste. São Cristóvão/CE, 2003.

MORAES, Carmen S. Vidigal; LOPES NETO, Sebastião. Educação, formação profissional e certificação de conhecimentos: considerações sobre uma política pública de certificação profissional. Educação e Sociedade, Campinas, vol. 26, n. 93, p. 1435-1469, set.-dez. 2005.

OLIVEIRA, Dalila Andrade. A Educação Básica e profissional no contexto das reformas dos anos 90 . Trabalho \& Educação, Belo Horizonte, n. 8, jan.-jun. 2001.

OLIVEIRA, Gilvan M. O lugar das línguas: A América do Sul e os mercados linguísticos na Nova Economia. Synergies Brésil, n. spécial 1, p. 21-30, 2010.

PACHECO, José Augusto. Escritos Curriculares. São Paulo: Cortez Editora, 2005.

PERNAMBUCO. Decreto 26.307, 15 jan. 2004. Cria o Programa de Desenvolvimento dos Centros de Ensino Experimental. (Revogada pelo art. 11 da Lei Complementar 125, 10 jul. 2008.) Pernambuco, 2004.

PERONI, Vera M. Vidal. A gestão democrática da educação em tempos de parceria entre o público e o privado. ProPosições, Campinas, v. 23, n. 2 (68), p. 19-31, maio-ago. 2012.

PERONI, Vera M. Vidal. As relações entre o público e o privado nas políticas educacionais no contexto da terceira via. Currículo sem Fronteiras, v. 13, n. 2, p. 234-255, maio-ago. 2013.

PETERS, Guy; PIERRE, John. Governance without governement? Rethinking public administration. Journal of Public Administration Research and Theory. v. 8, n. 2, p. 223-243, apr. 1998.

PIERANTI, Octávio P.; RODRIGUES, Silvia; PECI, Alketa. Governança e New Public Management: convergências e contradições no contexto brasileiro. O\&S: v. 15, n. 46, jul.-set. 2008.

POLIDORI, Marlis M.; CARVALHO, Nathan Ono. Acreditação de instituições de Educação Superior: uma necessidade ou uma normatização. Revista da Avaliação da Educação Superior. Disp.: <http://ipametodista.edu.br/ pos-graduacao/stricto-sensu/processo-seletivo/arquivos/acreditacao_de_instituicoes_de_educacao_superior_uma_ necessidade_ou_uma_normatizacao.pdf. Acesso: 06 set. 2016.

RAMOS, Natália. Sociedades multiculturais, interculturalidade e educação. Desafios pedagógicos, comunicacionais e políticos. Revista Portuguesa de Pedagogia, Coimbra, n. 41(3), 2007.

SANTA CATARINA. Decreto 1794/13, 15 out. 2013. Disp.: http://www.portaldoservidor.sc.gov.br/ckfinder/userfiles/ arquivos/Legislacao\%20Correlata/Portarias/2015-Portaria_N_24-SED_de_02_de_julho_de_2015.pdf. Acesso: 15 set. 2016.

SARDINHA, Rafaela Santos. O projeto Procentro e as escolas charter: investigação de um modelo educacional defendido pela Fundação Itaú Social. Rio de Janeiro: Dissertação (Mestrado em Educação) - Programa de Pós Graduação em Educação, UFRJ, 2013. Disp.: <http://www.educacao.ufrj.br/drafaelasardinha.pdf>. Acesso: 25 Out. 2016.

SAVIANI, Dermeval. Sistemas de ensino e planos de educação: o âmbito dos municípios. Educação e Sociedade, ano XX, n. 69, Dez. 1999.

SILVA, Mônica R. Currículo e competências: a formação administrada. São Paulo: Cortez, 2007. 
TEICHLER, Ulrich: The Changing debate on Internationalization of higher education. Higher Education, n. 48, p. 546, 2004.

YANAGUITA, A. I. As políticas educacionais no Brasil nos anos 1990. In: ANPAE. XXV Simpósio Brasileiro e II Congresso Ibero-americano de Política de Administração da Educação. Cadernos Anpae, v. 10. p. 1-13, 2011. Disp.: <http://www.anpae.org.br/simposio2011/cdrom2011/PDFs/trabalhosCompletos/comunicacoesRelatos/0004.pdf.

Acesso:20 out. 2016.

\section{RESUMO}

No texto em pauta, discuto a problemática da gestão curricular frente a uma agenda política de escala transnacional em curso. Como recorte, analiso a relação entre os sentidos acionados para a hegemonização desta agenda e as reverberações na gestão curricular, sobretudo em espaços locais. Avalio tratar-se de um movimento global único, articulado em torno de quatro frentes: internacionalização curricular, avaliação com estandardização, centralização curricular; e parcerização com o privado em ações curriculares. Situo alguns exemplos de deslocamento na gestão curricular decorrentes desta agenda e concluo destacando negociações mobilizadas por gestores para atender múltiplas demandas e interesses.

Palavras-chave: Currículo, Gestão Curricular, Redes Políticas, Agenda Transnacional.

\section{CURRICULUM ADMINISTRATION IN THE WEB OF POLITICAL NETWORKS ON A TRANSNATIONAL SCALE}

\section{ABSTRACT}

In this article I discuss the problematic of curriculum administration in light of a current transnational political agenda. I analyze the relationship between the meanings emphasized to establish the hegemony of this agenda and the repercussions for curriculum administration, particularly at a local level. I understand that it involves a single global movement, articulated around four fronts: curriculum internationalization, evaluation with standardization, curriculum centralization and partnership with the private sector in curriculum actions. I locate some examples of the shift in curriculum administration due to this agenda and conclude by highlighting negotiations mobilized by administrators to attend multiple demands and interests.

Keywords: Curriculum, Curriculum administration, Policy networks, Transnational Agenda.

Submetido em Set./2016 Aprovado em Dez./2016 